\title{
Clear Cell Hidradenocarcinoma of the Scalp: An Unusual Case of Sweet Gland'S Tumor
}

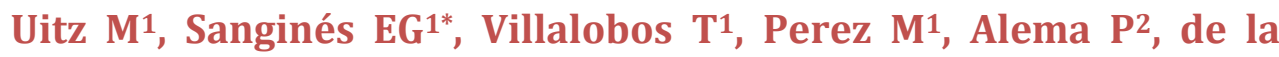 \\ Torre $\mathrm{FE}^{2}$, Estrada $\mathrm{FA}^{2}$, Araiza $\mathrm{DR}^{3}$ and Arredondo $\mathrm{A}^{4}$ \\ ${ }^{1}$ Dermatology service, Hospital Regional Licenciado Adolfo López Mateos, Mexico \\ 2Pathology service \\ ${ }^{3}$ Department otolaryngology \\ ${ }^{4}$ Radiology service
}

*Corresponding author: Esther Guvera Sanginés, MD. Dermatology service, Hospital Regional “Licenciado Adolfo López Mateos"Av Universidad. 1321, Col. Florida, Deleg Alvaro Obregón, ZIP 01030, Mexico, Tel: +52 (155) 540128 07; E-mail: eguevarasanginés@gmail.com

\section{Abstract}

Clear cell hidradenocarcinoma is a malignant tumor of the sweat glands that represents less than $0.001 \%$ of the skin appendages malignant tumors. The original description is attributed to Keasbey and Headley in 1954. Its origin can be primary or it can be developed on a pre-existing benign neoplasm [1-3]. This neoplasm mainly affects male patients with an average age of 50. The most frequent topographic location is on the head followed by the neck and extremities [3]. In most of the cases, it is presented as a solitary tumor of a variable size of 1 to $5 \mathrm{~cm}$, not well demarcated, either ulcerated or not. Typically, asymptomatic, slow growing and developing metastases approximately $60 \%$ within the first 2 years, the 5-year survival rate, is less than 30\% [3]. The diagnosis is confirmed by a histopathologic study. The treatment of choice is a surgical procedure with wide margins. Other alternatives are chemotherapy and radiotherapy [3].

Key words: Clear Cell Hidradenocarcinoma; Dermatosis; Neoplasm; Retroarticular region; Sweat glands

\section{Case Report}

A 54-year-old male patient was seen for dermatosis located in the head on the parietal-temporal and left retroarticular region, which consisted on 2 exophytic neoformations of $13 \times 13 \mathrm{~cm}$ and $12 \times 10 \mathrm{~cm}$ of diameter respectively, that have a crateriform appearance, ulcerated, with dirty bottom, necrotic tissue in its surface, purulent exudate, erythematosus, smooth, bright, infiltrating edges with telangiectasia [Figures 1A and 1B]. The patient mentioned that the dermatosis was noted in
2012, following a mild traumatic brain injury with the presence of a rapidly enlarged asymptomatic tumor.

The histopathological study revealed an infiltrating neoplasm with extension from the superficial dermis to the subcutaneous cellular tissue [Figure 2A], of epithelial origin formed by vacuolated clear cytoplasm pleomorphic cells with oval, irregular contour, notched nucleus and abnormal mitosis. There was a squamous component. The neoplastic cells were display in strands inside a mucinous lax stroma [Figure 2B] with perineural invasion. 
Therefore, he was diagnosed with clear cell hidradenocarcinoma [Figure 2C].

The immune histochemistry test was positive to: epithelial membrane antigen, $\mathrm{CD} 10$, an antibody associated with breast human carcinoma (BCA 225), cytokeratin 5/6, cytokeratin 7 , p53 in $90 \%$ of the neoplastic cells and $30 \%$ of positivity to Ki 67 .

Extension studies CAT, MR, PET-SCAN, performed in 2012, exhibited the tumor located up to the subcutaneous cellular tissue. Treatment was initiated with cetuximab (5 sessions) with no response.

In 2014, a PET- SCAN control was performed and it showed bone marrow infiltration to the inner sheet and no metastasis were found.

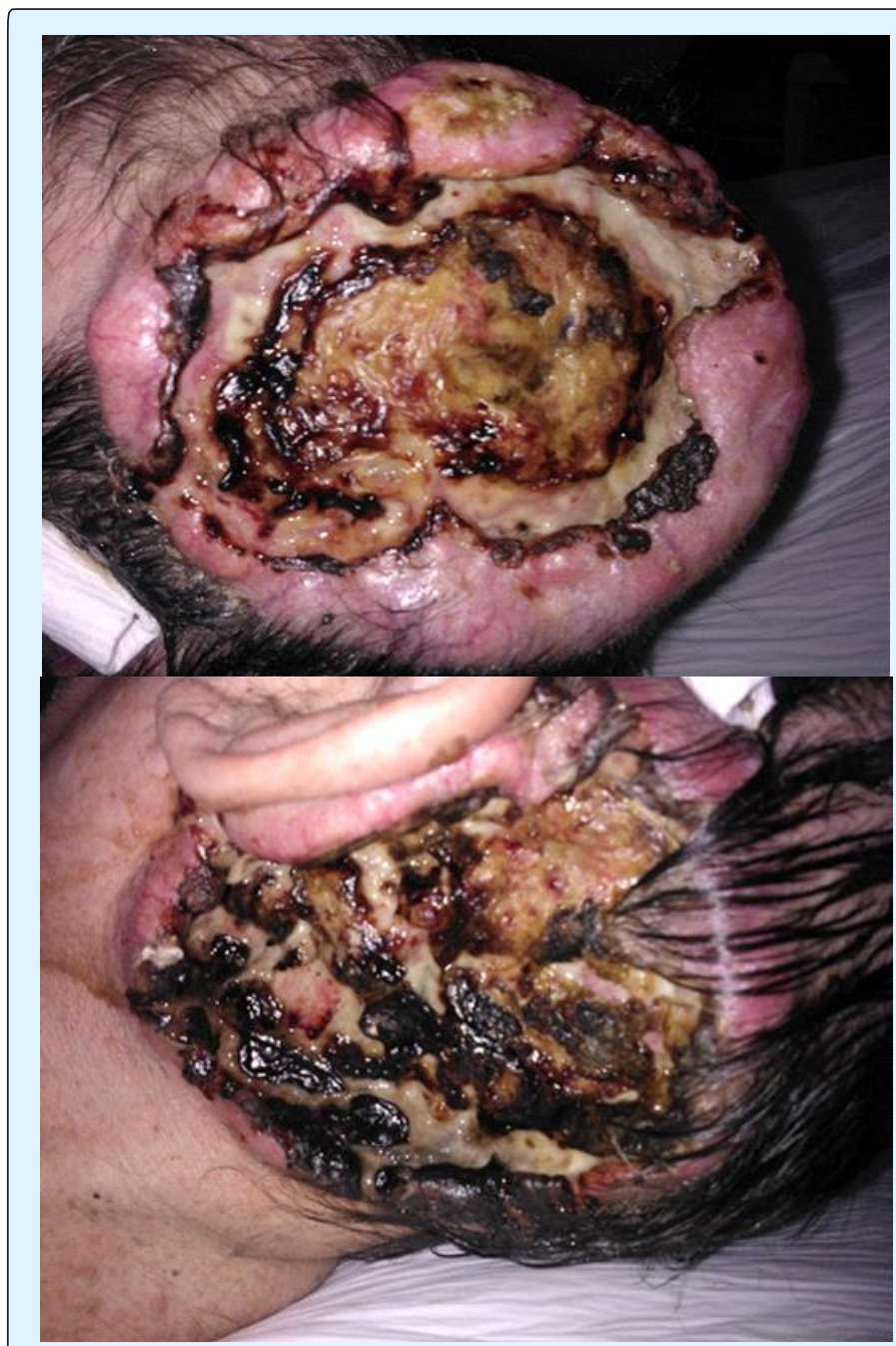

Figure 1: (a) Neoformation in the left parietal-temporal and left retroarticular region.

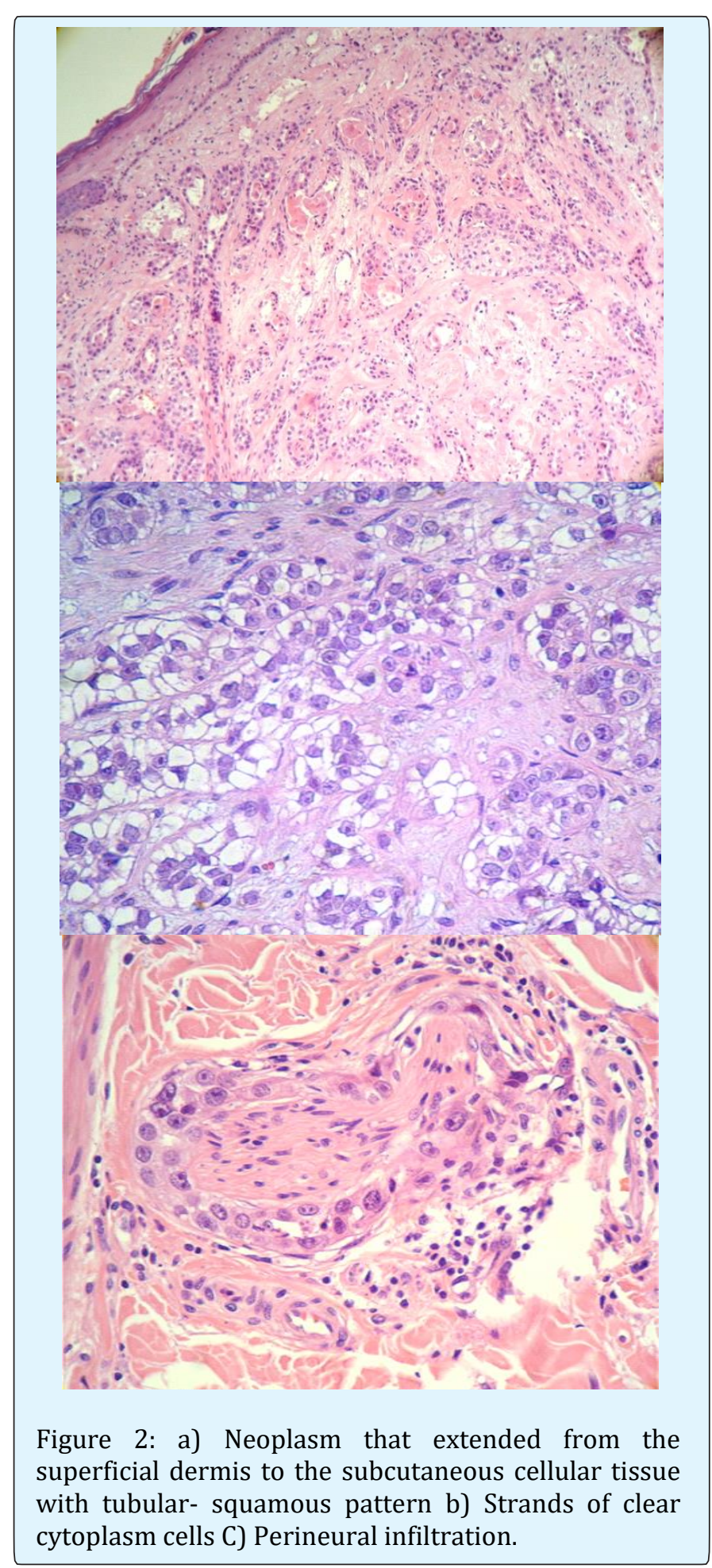

A palliative resection was made and chemotherapy and radiotherapy treatments, 8 months later the patient died due to meninges infiltration. 


\section{Discussion}

Clear cell hidradenocarcioma is a malignant tumor of the skin appendages with a great degree of malignancy and high a potential for metastasis. It have been reported less than 100 cases in the world, it can be the result of a benign neoplasia mainly from nodular hidradenoma or de novo hidradenoma, in the secretory part ducts of the sweat ecrine or apocrine glands [1-3].

The diagnosis is complex and through the years it has received different denominations, including: clear cell papillary carcinoma, clear cell malignant hidradenoma, malignant eccrine acrospiroma, malignant eccrine carcinoma, clear cell eccrine carcinoma, nodular hidradenocarcinoma, malignant eccrine hidradenoma, in 1998 Geisse and McCallmont suggested the term Clear Cell Hidradenocarcinoma which is as we refer to it currently $[3,4]$.

The clear cell hidradenocarcinoma is clinically manifested in the form of a solitary tumor of a variable size between 1 to $6 \mathrm{~cm}$ of diameter, not well demarcated, red, ulcerated or not, asymptomatic, slow-growing and suddenly with a rapid increase in the volume [5,6]. Manly affects male patients, with an average age of 50 . The most frequent topographic location is in the head followed by the thorax, neck and extremities. Also it has been described in lip, eyelid, vulva and in the anogenital region [5-10].

It is a recurrent aggressive tumor with metastasic capacity mainly to the lymph nodes, lungs and bones. Less often in: spleen, liver, pleura, pericardium and myocardium [11-14].

Histologically is a multilobuled intradermal neoplasm formed by solid or solid-cystic islets, wherein tubular differentiation can be identified, the silhouette is irregular and asymmetric with invasion of nearby structures, without any connection with the epidermis [11-14].

It has several types of cells: clear, pale, squamous, polygonal or mucinoses. The clear or pale cells owe their morphology to the abundant glycogen content in its cytoplasm. The squamous cells present a wide, eosinophilic, of a granular appearance cytoplasm and sometimes laid out in a whirlpool formation. The mucinous cells are generally limited and are located preferably in the luminal edge of the tubular structures, show a wide cytoplasm, of a basophilic and granular appearance [13-15].
In some areas, the cells that coat the tubules are display in a double row, with columnar cells that show secretion due to decapitation in the luminal edge and cuboidal cells in the peripheral row.

The malignancy indicators are cellular pleomorphism, atypical cells, an intense mitotic activity, angiolymphatic and perineural invasion, loss of circumscription, scattered growth pattern, depth of the extension, necrosis, clefts between the tumor and stroma [13-15]. Positivity was found in the immunohistochemistry to the carcinoembryonic antigen (CEA), epithelial membrane antigen (EMA), cytokeratins (CK AE1/3+, CK5/6+, CK19, CAM5.2), in a lower frequency for estrogenic receptors, GCDFP-15, protein S-100 and Her-2/neu (human epidermal growth receptor 2) related with metastasis, intense positivity expressed in large percentage of neoplastic cells for Ki 67 y p53 [16,17].

The differential diagnoses include primary skin tumors with follicular differentiation, sebaceous or sweat glands differentiation. As well as renal, lung and hepatic metastasic carcinoma.

Due to the fact that the hidradenocarcinoma is extremely rare, a clinical guide does not exist to approach it. A wide surgical resection with margins between 3 to 5 $\mathrm{cm}$ is suggested. However, the rates of a local recurrence are of $10 \%$ to $50 \%$. Mohs surgery has the lowest recurrence rate in large tumors $[18,19]$.

Adjuvant therapy includes 5-fluorouracil as first line treatment ( $425 \mathrm{mg} / \mathrm{m}^{2} /$ day 1 to 5 days); the second line is doxorubicin: (75mg/m² 1 day) and cisplatin $\left(100 \mathrm{mg} / \mathrm{m}^{2} 1\right.$ day). Radiotherapy is used as an adjuvant treatment in the adjustment of the tumors with positive margins, in the complete resection of large tumors, recurrent and with an invasion to the lymph nodes $[19,20]$.

Recently, the anti-Her-2/neu therapy (trastuzumab) has been used in patients with metastases, with satisfactory results.

\section{References}

1. Santa Cruz DJ (1987) Sweet gland carcinoma o comprehensive review. Sem Diagn Pathol 4(1): 38-74.

2. Keasby LE, Hadley GC (1954) Clear cell hidradenoma: Report of three cases with widespread metastases. Cancer 7(5): 934-952. 
3. Ohta M, Hiramoto M, Fujii M, Togo T (2004) Nodular Hidradenocarcinoma on the Scalp of a Young Woman: Case Report and Review of literature. Dermatol Surg 30(9): 1265-1268.

4. Pohar-Marinsek Z, Lamovec J (2003) Clear cell hidradenocarcinoma. Acta Dermatoven 12(3): 94-99.

5. Cohen M, Cassarino DS, Shih HB, Abemayor E, St John M (2009) Apocrine Hidradenocarcinoma of the Scalp: A Classification Conundrum. Head Neck Pathol 3(1): 42-46.

6. Massad LS, Bitterman P, Clarke-Pearson DL (1996) Metastatic clearcell eccrine hidradenocarcinoma of the vulva: survival after primary surgical resection. Gynecol Oncol 61(12): 287-290.

7. Ruiz R, Galan M, Husein H, María Martinez J (2013) Hidroadenocarcinoma apocrino. Piel 28(10): 620622.

8. Khalil H, Yusuf H, Kaddour H (2003) Malignant eccrine hidradenoma of neck causing acute heart failure. Auris Nasus Larynx 30(3): 307-310.

9. Al Baghli A, Reddy SS, Reddy MA (2010) Malignant Nodular Hidradenoma of the Eyelid: A Rare Sweat Gland Tumor. East Afr J Ophthalmol 17(4): 374-376.

10. Singh G, Narasimha A, Kumar H, Datti N (2013) Clear cell hidradenocarcinoma of the eyelid: a case report with a review of the literature. Int Ophthalmol 33(2): 171-175.

11. Liapakis IE, Korkolis DP, Koutsoumbi A, Fida A, Kokkalis G, et al. (2006) Malignant Hidradenoma: A Report of Two Cases and Review of the Literature. Anticancer Res 26(3): 2217-2220.

12. Hemalatha AL, Yeshwanth $\mathrm{R}$, Anoosha K, Ashok KP, Sushma HM (2014) Malignant Nodular HidradenomaA Distinctly Rare and Diagnostically Challenging Sweat Gland Tumor. NJLM 3(3): 20-22.
13. Oviedo I, Ferri B, Martínez E (2010) Hidradenocarcinoma originado en hidradenoma nodular: descripción de un caso. Rev Esp Patol 43(1): 47-51.

14. Fernande DJR (2011) Neoplasias malignas de anexos cutáneos. Experiencia de 247 casos. Patología Rev Latinoam 49(1): 11-24.

15. Kazakov DV, Michal M, Kacerovska D, Mckee PH (2012) Lesions with Predominant Apocrine and Eccrine Differentiation. In: Kazakov D. Michal M. Kacerovska D, Mckee PH (Eds.), Cutaneous Adnexal Tumors. Philadelphia: Lippincott Williams \& Wilkins pp. 99-104.

16. Nazarian RM, Kapur P, Rakheja D, Piris A, Duncan LM, et al. (2009) Atypical and malignant hidradenomas: a histological and immunohistochemical study. Mod Pathol 22(4): 600-610.

17. Kazakov DV, Ivan D, Kutzner H, Spagnolo DV, Grossmann P, et al. (2009) Cutaneous Hidradenocarcinoma: A. Clinicopathological, Immunohistochemical, and Molecular Biologic Study of 14 cases, Including Her2/neu Gene expression/amplification, TP 53 Gene Mutation Analysis, and $\mathrm{t}(11 ; 19)$ Translocation. Am J Dermatopathol 31(3): 236-247.

18. Yavel R, Hinshaw M, Rao V, Hartig GK, Harari PM, et al. (2009) Hidradenomas and a hidradenocarcinoma of the Scalp Managed Using Mohs Micrographic Surgery and a Multidisciplinary Approach: Case Reports and Review of the Literature. Dermatol Surg 35(2): 273-281.

19. Amel T, Olfa G, Faten H, Makrem H, Slim BA, et al. (2009) Metastatic hidradenocarcinoma: Surgery and chemotherapy. N Am J Med Sci 1(7): 372-374.

20. Lalya I, Hadadi K, Mehdi E, Lalya I, Bazine A, et al. (2011) Radiotherapy on hidradenocarcinoma. North Am J Med Sci 3(1): 43-45.

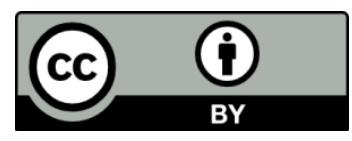

